\title{
COMMENTS ON X-RAYS EMITTED BY THE SUN
}

\author{
by John C. LINDSAY \\ (Goddard Space Flight Center Greenbelt, Maryland, U. S. A.)
}

REsumf. - A partir des observations obtenues à bord du premier satellite O. S. O., on peut fixer une limite supérieure de 3,40 $\pm 0,95$ photons $/ \mathrm{cm}^{2} . s$ au flux de rayons $X$ d'énergie comprise entre 20 et $100 \mathrm{keV}$ émis par le Soleil " calme ". On a enregistré huit sursauts brefs, à montée rapide, associés d̀ des éruptions optiques et d̀ des sursauts centimétriques. Le flux de rayons $X$ de $2 \dot{a} 8 \AA$ semble provenir des plages. L'intensité de ce dernier rayonnement est très variable, les variations pouvant atteindre $5 \%$ par heure.

ABstract. - Observations from the first Orbiting Solar Observatory have set an upper limit of $3.40 \pm 0.95$ photons/cm ${ }^{2} . s$ for the 20-100 keV X-ray flux from the " quiet" Sun. . Eight impulsive and short-lived 20-100 keV X-ray bursts were observed which were associated with optical flares and cm radio bursts. The 2-8 $X$-ray flux from the "quiet" Sun was observed to be associated with plage groups on the Sun. The intensity for this $2-8 \AA X$-radiation was found to be quite variable, changes of $5 \%$ being observed almost hourly.

Резюме. - Исходя из наблюдений полученных на борту первого спутника O.S. О., можно установить верхний предел в $3,40 \pm 0,96$ фотонов $/ \mathrm{cm}^{2}$ с для потоков лучей $\mathrm{X}$ с энергией заключенной между 20 и 100 кэв, излучаемых спокойным Солнцем. Зарегистрированы восемь коротких всплесков, с быстрым подъёмом, связанных с оптическими вспышками и с сантиметровыми всплесками. Поток лучей $\mathrm{X}$ от 2 до $8 \AA$ по-видимому происходит из краев. Интенсивность этого последнего излучения очень переменна, изменения будучи в состоянии достигать $5 \%$ за час.

\section{INTRODUCTION}

There already have been several solar X-ray papers given at this symposium; therefore, the observations presented below are restricted to brief comments related to solar $\mathrm{X}$-radiation of 20-100 $\mathrm{KeV}$ energy and of wavelengths longer than $1 \AA$.

\section{0-100 KeV X-rays :}

OSO-1, in an orbit with a $33^{\circ}$ inclination angle with respect to the earth's equator, spent about two thirds of the time in sunlight and about one third occulted by the earth. This orbit had a period of approximately 90 minutes. The data were recovered from on-board data tape recorders that performed satisfactorily for approximately three months, or for about 1000 hours of observation.

Frost [1] utilized a scintillation counter consisting of a cylindrical $\mathrm{NaI}(\mathrm{T} 1)$ crystal $0.3 \mathrm{~cm}$ high and $2.24 \mathrm{~cm}$ in diameter coupled to a RCA C-7151 multiplier-phototube to study $20-100 \mathrm{KeV}$ solar X-rays. From orbits in which all solar indices indicated a " quiet" Sun, the response of the detector to background and to regions of trapped radiation was determined. Observations for regions free of trapped radiation gave a count rate between 10.5 and 14.5 counts per second. From these data the $20-100 \mathrm{KeV}$ flux from the " quiet " Sun was estimated to have an upper limit of $3.40 \pm 0.95$ photons $/ \mathrm{cm}^{2}$-s.

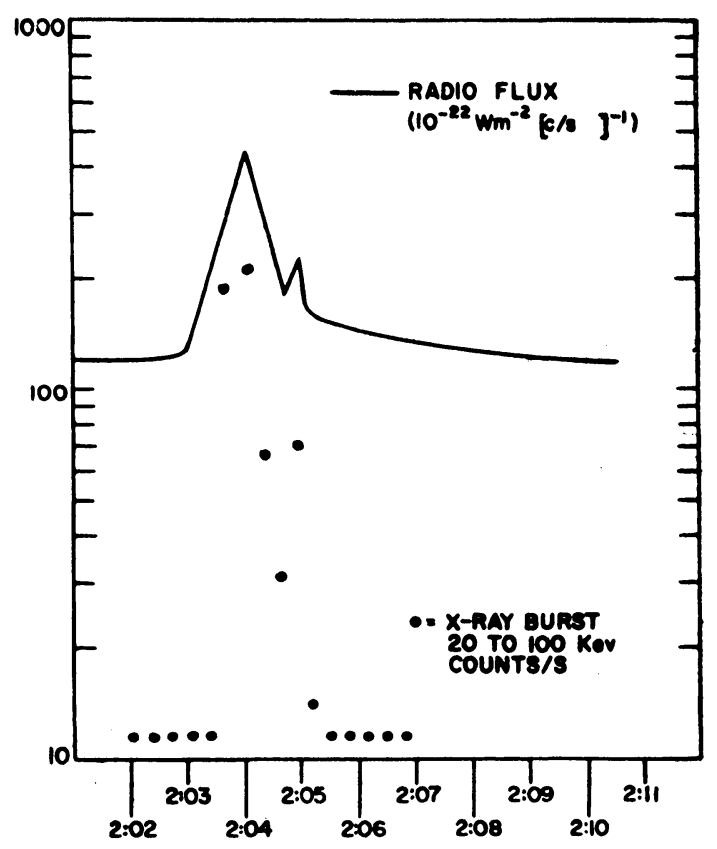

FIG. 1. - Comparison of OSO-1 X-ray burst data with radio data from the Research Institute of Atmospherics, Nagoya University. 
For the 1000 hours for which reasonably continuous data existed, a search was made for high energy X-ray bursts. During this time period eight such events were found.

One of these events occurred on 17 March 1962, between 19:39:5 and 19:40:30 and coincided with a flare which was observed by the Lockheed Solar Observatory between 19:36 and 20:03 U. T. Also at this time, an impulsive radio burst of three minutes duration, beginning at 19:39 U. T. and reaching a maximum at 19:40:12 U.T. was observed at $2800 \mathrm{MHz}$ by Ottawa. MoReton [2] has pointed out that for nine $\mathrm{X}$-ray burst events (including this one) for which optical data were available, all nine have been associated with " explosive" type flares.

It has been proposed by DE JAGER at this symposium that this type of X-ray event is a Class II $a$ impulsive and short-lived burst. From the data available it is believed that all eight events observed by OSO-1 fit into this classification. However, it is interesting to note that two of these events are different in that the $\mathrm{X}$-ray flux measurements show a double peak, Figure 1. Also shown are $3750 \mathrm{MHz}$ radio data supplied by The
Research Institute of Atmospherics, Nagoya University, Toyokawa, Aichi, Japan, that also have a double peak. Within the accuracy with which time can be determined the $\mathrm{X}$-ray and radio data coincide extremely well. The double peak raises interesting questions concerning the generation mechanism for these $\mathrm{X}$-ray bursts.

\section{Components of the 2-8 $\AA X$-ray Flux :}

The observations from OSO-1 of the 2-8 $\AA$ X-ray flux by WHITE [3] utilizing a beryllium window ionization chamber filled with xenon gas disolosed the dynamic character of solar X-ray emission. For example, as contrasted with the 2800-MHz radio observations, only 3 occasions out of 70 days (7 March through 15 May 1962) was the X-ray flux "quiet" (less than $5 \%$ variation) for an interval of as much as 8 hours (WHITE [3]). Changes occurred in certain cases asrapidly asa fraction of a second, with others occuring slowly over many days.

The slowly-varying component of $\mathrm{X}$-ray flux can be attributed to plage activity being carried onto and off of the solar disk as the sun rotates. This effect is shown clearly in Figure 2, in which

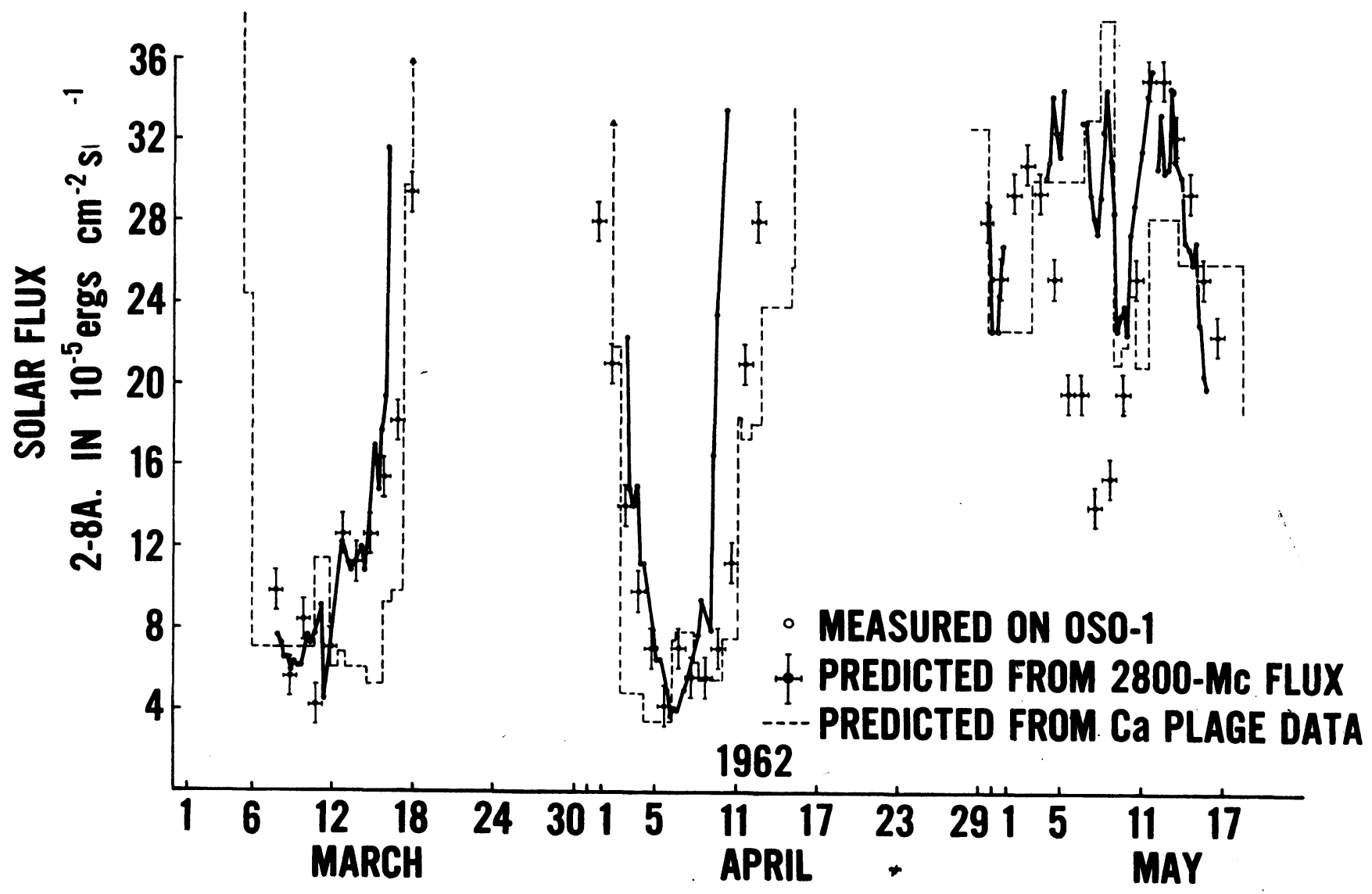

Fra. 2. - Slowly-varying component of Solar X-ray flux. 
WHITE has made an effort to correlate the slowlyvarying component of the solar $\mathrm{X}$-ray flux with the Ca plage data (area of brightness) and with 2800-MHz flux. There are obvious difficulties with fitting these data, however, they do establish that plage activity is the major source of non-flare 2-8 \& solar X-rays.

\section{Source of "Quiet" Sun X-ray:}

In an effort to learn more about the source of solar X-ray, R. GiacconI ( ${ }^{1}$ ) and the author [4] have undertaken a series of rocket experiments utilizing grazing incidence optical telescopes to photograph the Sun in X-rays. These telescopes consist of segments of a paraboloid and a confocal hyperboloid to form a real image at the focal plane. Filters are used to select the band of wavelengths photographed. The first flight of such a system was made from White SANDS, New Mexico, on October 15, 1963, using a Ball Brothers Research Corporation pointing control on an Aerobee rocket.

Due to the fact that the pointing control provides

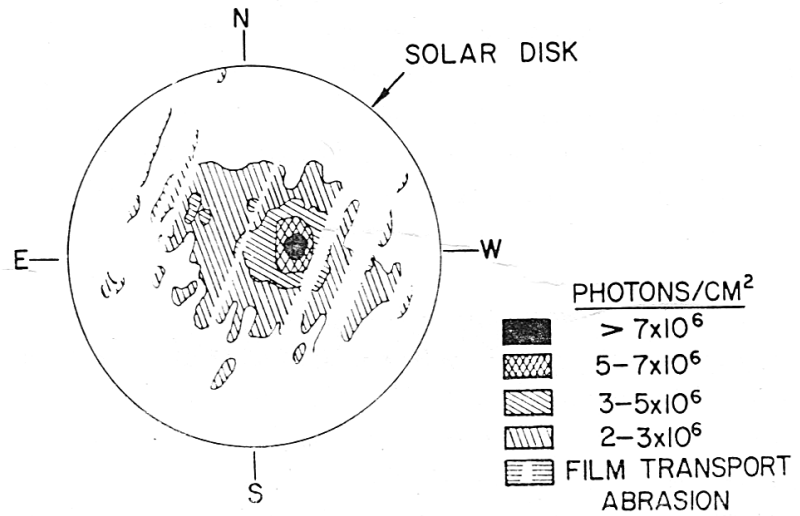

Ilu. 3. - Microdensitometer trace of a photograph of the Sun in 8-10 $\AA$ X-rays. October 15, 1963. Scanning aperture $=240 \times 240$ Microns.

(1) American Science \& Engineering, Inc., Cambridge, Mass. only two axis of stabilization, there can be smearing of the image caused by the rocket precessing around a yaw cone. In the October 15th flight the rocket developed into a rather large yaw cone with a very slow precession rate so that smearing of the image was small for reasonable exposure times.

A microdensitometer trace of the photograph obtained for wavelengths between $8-20 \AA$ is shown in figure 3 . The attitude of the rocket has been very difficult to determine ; however, it is believed that the contour map is located within the angular resolution of the photograph ( 1 to 2 min of arc). This is approximately the limit in the pointing accuracy. The $9.1 \mathrm{~cm}$ radio emission obtained at Standord is shown in Figure 4.

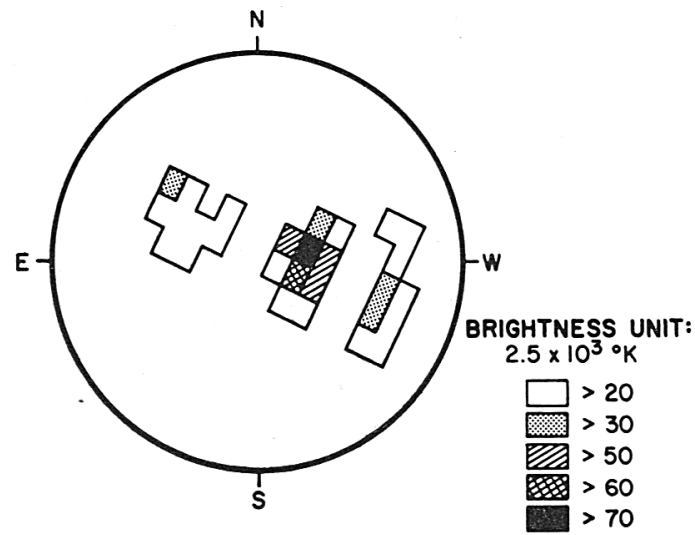

Fig. 4. - The Solar $9.1 \mathrm{~cm}$ Radio Emission (obtained at StanFord), October 15, 1963. 20-21 HRS. U. T.

The similarity is obvious, which was to be expected from the 2-11 $\AA \mathrm{X}$-ray data discussed above. Also, the most intense source of $\mathrm{X}$-rays is only 1.5 to $3 \mathrm{~min}$ of arc across, which may be smaller when one takes into account the jitter of approximately $1 \mathrm{~min}$ of arc in the pointing control.

Manuscrit reçu le $1^{\mathrm{er}}$ mars.

\section{REFERENCES}

[1] Frost K. J., 1964, Comments on High Energy X-ray Bursts Observed by OSO-1, AAS-NASA Symposium on the Physics of Solar Flares. NASA SP-50, pp. 139-143.

[2] Moreton G. E., 1964, The Association of Bremsstrahlung X-rays with Explosive Flares, AAS-
NASA Symposium on the Physics of Solar Flares. NASA SP-50, pp. 209-212.

[3] White W. A., Solar X-rays ; A Comparison with Microwave Radiation, AAS-NASA Symposium on the Physics of Solar Flares. NASA SP-50, pp. 131-137.

[4] Giacconi R. and Lindsay J. C., To be published. 